\title{
ECJSE
}

Makale / Research Paper

\section{Çözelti Plazması Yöntemiyle Sentezlenen Gümüş Nanoparçacık Boyutuna Gerilim ve Çalışma Süresinin Etkisi}

\author{
Mehmet ÖZKAN $^{1 *}$, Ali SAKARYA ${ }^{2}$ \\ ${ }^{1}$ Afyon Kocatepe Üniversitesi, Fen Edebiyat Fakültesi, Fizik Bölümü, 03200, Afyonkarahisar/TÜRKİYE \\ ${ }^{2}$ Afyon Kocatepe Üniversitesi, Fen Bilimleri Enstitüsü, 03200, Afyonkarahisar/TÜRKIYE \\ a*mozkan@aku.edu.tr
}

Received/Geliş: 08.05.2019

Accepted/Kabul: 03.07.2019

\begin{abstract}
Öz: $\mathrm{Bu}$ çalışmada, gümüş nitrat tuzu içeren sulu çözelti içerisinde çift kutuplu doğru akım güç kaynağı ile plazma oluşturulmuştur. Oluşturulan plazma sistemi ile metalik gümüş nanoparçacıklar sentezlenmiştir. Çalışma öncesinde ve çalışma esnasında optik emisyon ölçümleri yapılmış ve plazma oluşumunda suyun ayrışması sonucu hidrojen $(655 \mathrm{~nm}$ de $\mathrm{H} \alpha, 480 \mathrm{~nm}$ de $\mathrm{H} \beta, 775 \mathrm{~nm})$, oksijen $(775 \mathrm{~nm})$, hidroksil $(306 \mathrm{~nm})$ radikallerinin oluşumu spektrum piklerinde gözlenmiştir. Çalışma esnasında uygulama voltajı sırasıyla 500, 1000 ve $1500 \mathrm{kV}$ olarak değiştirilmiş ve her bir voltaj değerinde 10,20 ve 30 dakikalarda numuneler alınarak, XRD ve FESEM'le nanoparçacıklar karakterize edilmiştir. Ayrıca UV-Vis Spektrofotometre ile çözeltideki gümüş iyonları konsantrasyon değişimi incelenmiștir. Sentezlenen gümüş nanoparçacıkların boyutlarının süre artışı ile küçüldüğü ve 30 dakika sonunda 10 ile $40 \mathrm{~nm}$ boyutlarına ulaştığı gözlenirken. Voltaj artışının sadece ilk 10 dakika süresinde etkili olduğu anlaşılmıştır.
\end{abstract}

Anahtar Kelimeler: Plazma; Plazma; Çözelti Plazması; Nanoparçacık; Gümüş Nanoparçacık.

\section{The Effect of Voltage and Working Time on Silver Nanoparticle Size Synthesized by Solution Plasma Method}

\begin{abstract}
In this study, plasma was formed with bipolar direct current power supply in aqueous solution containing silver nitrate salt. Metallic silver nanoparticles were synthesized by the plasma system. Optical emission measurements were performed before and during the study, and hydrogen (655 nm, Ha, Hb, $775 \mathrm{~nm}$ ), oxygen $(775 \mathrm{~nm})$, hydroxyl $(306 \mathrm{~nm})$ radicals were observed at the spectrum peaks. During the operation, the application voltage was changed to 500,1000 and $1500 \mathrm{kV}$ respectively, and samples were taken at 10, 20 and 30 minutes at each voltage value and XRD and FESEM and nanoparticles were characterized. In addition, the concentration change of silver ions in solution with UV-Vis Spectrophotometer was investigated. The size of the synthesized silver nanoparticles decreased with increasing time and it was observed that it reached 10 and $40 \mathrm{~nm}$ dimensions after 30 minutes. The voltage increase was only effective in the first 10 minutes.
\end{abstract}

Keywords: Plasma; Solution Plasma; Nanoparticle; Silver Nanoparticle.

\section{Giriş}

Giderek önem kazanan bir bilim dalı olan nanoteknoloji etkisini gün geçtikçe daha da fazla hissettirmektedir. Özellikle nanoparçacık üretim yöntemleri önemli araştırma konusu olmaktadır. $\mathrm{Bu}$ kapsamda gümüş nanoparçacıklar $(\mathrm{AgNp})$ optik, yüksek elektriksel iletkenlik, yüksek termal iletkenlik ve anti bakteriyel özellikler gibi benzersiz fiziksel ve kimyasal özelliklere sahip olmasından dolayı sağlık sektöründe ve endüstriyel uygulamalarda çok fazla kullanılmaktadır. Elektro kimyasal depolama, ultraviyole 1şınlama ve elektron transfer tekniği gibi üretim tekniklerine sahip [1-6] AgNp ların farklı bir nanoparçacık üretim yöntemi olan sulu çözelti içinde oluşturulan 
elektriksel deşarj ile de sentezlenmesi mümkündür. Bu yöntemin adı literatürde "Çözelti Plazması Yöntemi” (ÇPY) olarak isimlendirilmiştir [7].

Nanoparçacık sentezinde çözelti plazması yöntemi katı ve gaz faz plazmaya göre gelecek vadetmektedir. Sıvı fazın moleküler yoğunluğu gaz faza göre daha yüksek olduğundan düşük sıcaklıklarda daha yüksek reaksiyon hızları beklenmektedir [8].

Çözelti plazmasının detaylı yapısı literatürde açık olarak yer almamaktadır [7]. Çözelti plazması için bir model Şekil-1' de verilmiştir. Çözelti içinde oluşan plazmanın etrafında gaz tabakası, gaz tabakasının etrafinda da sıvı tabakanın yer aldığı görülmüştür.

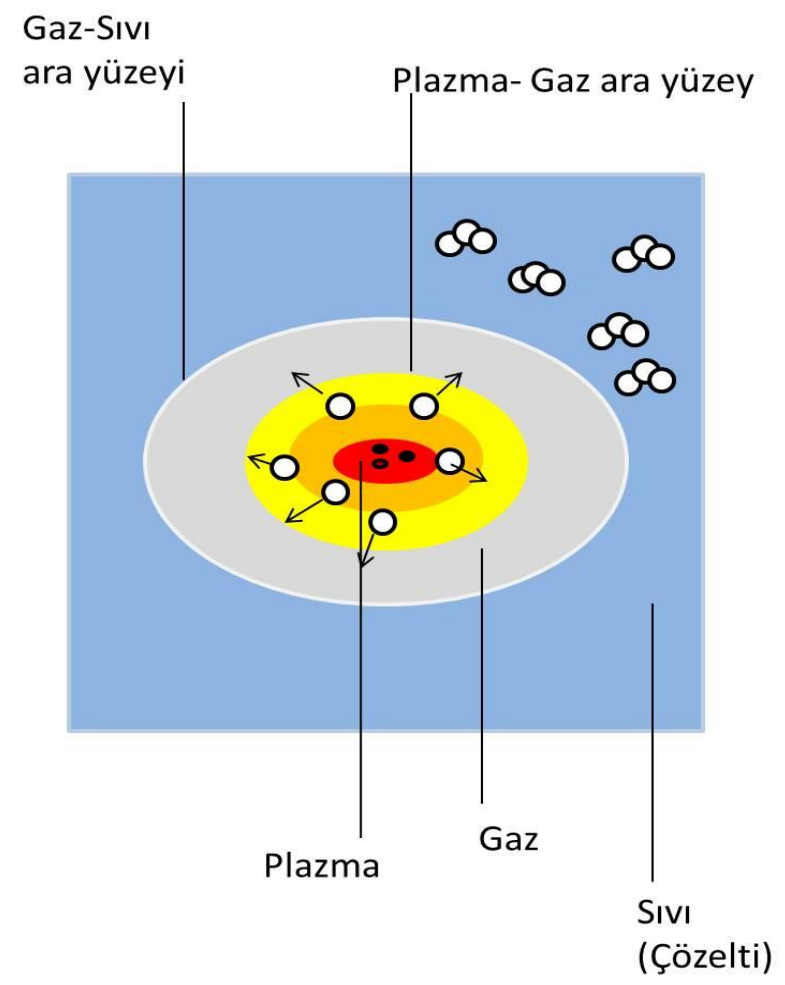

Şekil 1. Çözelti Plazması Modeli [7]

Çözelti içerisinde radikaller $(\mathrm{H} \bullet, \mathrm{O} \bullet, \mathrm{OH} \bullet)$, ultraviyole 1şınları, yüksek enerjili elektronlar ve şok dalgaları içeren plazma süreci, aktif türlerin ortaya çıkmasını sağlayarak herhangi bir indirgeyici ajana ihtiyaç duymadan çeşitli etkili kimyasal reaksiyonlara neden olduğu bilinmektedir[8-12]. Yöntemin bu özelliği nanoparçacık sentezi, polimer kırma, kimyasal indirgeme ve sterilizasyon amaçlı çalışmalarda kullanılabilirliliğini ortaya koymuştur [9-12].

$\mathrm{Bu}$ çalışmada çözelti plazması yöntemi kullanılarak gümüş nanoparçacık sentezi gerçekleştirilmiştir. Gümüş nanoparçacık sentezi sırasında uygulanan geriliminin ve uygulama süresinin, sentezlenen gümüş parçacıkların $(\mathrm{AgNp})$ boyutuna olan etkisi alan emisyon taramalı elektron mikroskobu (FESEM) ve X ışınları kırınımı (XRD) metodlarıyla karakterize edilmiştir.

\section{Deneysel Çalışma}

Gümüş nanoparçacık sentezi için oluşturulan deney düzeneği Şekil-2' de gösterilmiştir. Deney düzeneğinde; çift kutuplu 0-4 kV gerilim, 1-30 kHz frekans ve 0-4 $\mu$ s puls genişliği sağlayan puls DC güç kaynağı, güç kaynağına bağlı seramik tutucular içerisinde birbirlerine $3 \mathrm{~mm}$ uzaklıkta konumlandırılmış tungsten elektrotlar, tepkime hücresi olarak karşılıklı elektrot girişi bulunan 150 ml' lik cam erlen ve tepkime sırasında çözeltinin derişiminin tepkime hücresinin her yerinde eşit tutmak amacıyla manyetik karıştırıcı kullanılmıştır. 


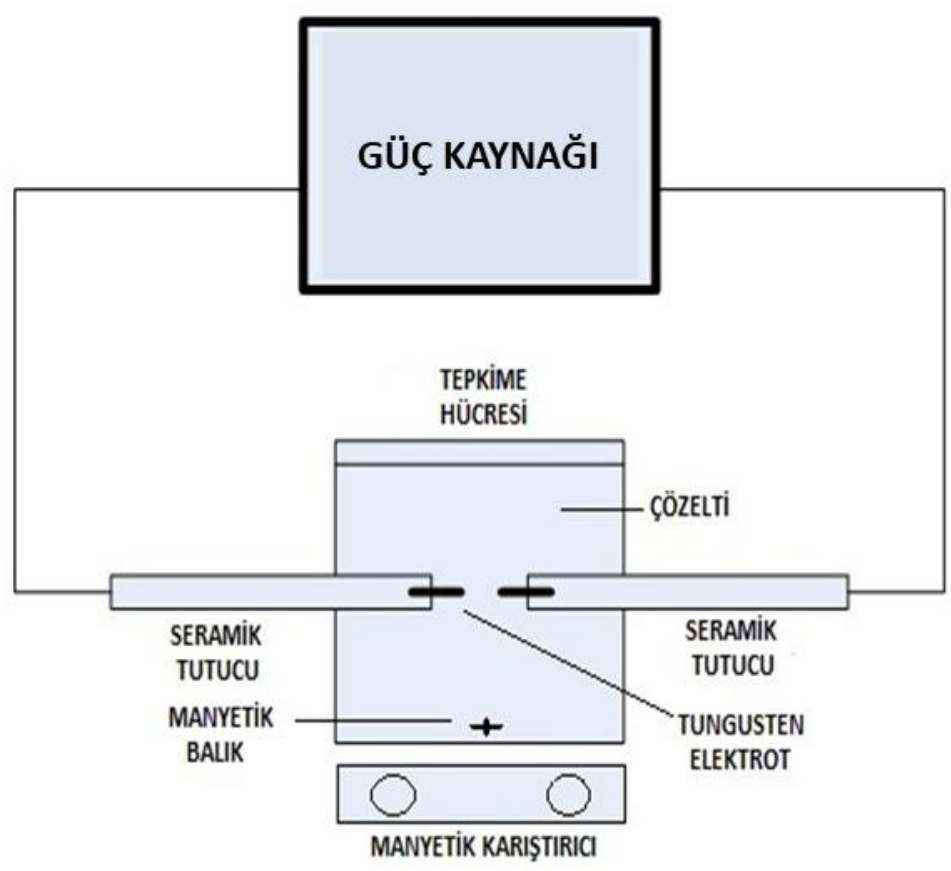

Şekil 2. Gümüş Nanoparçacık Sentezi Deney Düzeneği

$100 \mathrm{~mL} 25 \mathrm{mM}$ gümüş nitrat $\left(\mathrm{AgNO}_{3(\mathrm{k})}\right)$ saf çözeltisi $\left(\mathrm{AgNO}_{3(\mathrm{aq})}\right)$ hazırlanmıştır. Hazırlanan gümüş nitrat çözeltisi tepkime hücresine konularak manyetik karıştırıcı ile 400 devir/dakika hızında çözeltinin sürekli karıştırılmıştır. Manyetik karıştırıcıyla karıştırılan çözeltiye çift kutuplu puls DC güç kaynağ 1 ile $15 \mathrm{kHz}$ frekanslı, $2 \mu$ s puls genişliğine sahip $0.5 \mathrm{kV}$ ' lik gerilim uygulanarak çözelti içerisinde sürekli plazmanın oluşması sağlanmıştır. Tepkime başladıktan sonra 10. dakikada, 20. dakikada ve 30. dakikada 5' er ml' lik örnekler cam pipet yardımıyla tepkime hücresinden çekilip örnek tüplerine alınmıştır.Aynı işlemler sırasıyla $1 \mathrm{kV}$ ve $1.5 \mathrm{kV}$ ' lik gerilimler uygulanarak tekrarlanmıştır. Yapılan seri deneyler neticesinde toplamda 9 örnek alınmıştır. Alınan örneklerin özel durum kodları Tablo-1' de gösterilmiştir.

Tablo 1: Alınan Örneklerin Özel Durum Kodları

\begin{tabular}{cccc}
\hline Gerilim & $\mathbf{1 0} \mathbf{d k}$ & $\mathbf{2 0} \mathbf{d k}$ & $\mathbf{3 0} \mathbf{d k}$ \\
\hline $\mathbf{0 . 5} \mathbf{~ k V}$ & A1 & A2 & A3 \\
$\mathbf{1 ~ k V}$ & B1 & B2 & B3 \\
$\mathbf{1 . 5} \mathbf{~ k V}$ & C1 & C2 & C3 \\
\hline
\end{tabular}

\section{Bulgular ve Tartışma}

Plazma oluşmadan önce ve plazma oluştuktan sonra tepkime hücresinin optik emisyonları incelenmiştir. Elde edilen spektrumlar Şekil-3' de sırasıyla gösterilmiştir. Plazma oluşmadan önce ortamın optik emisyon spektrumu alınırken, plazma oluşumunda suyun ayrışması sonucu hidrojen (655nm de $\mathrm{H}_{\alpha}, 480 \mathrm{~nm}$ de $\left.\mathrm{H}_{\beta}, 775 \mathrm{~nm}\right)$, oksijen $(775 \mathrm{~nm})$, hidroksil (306 nm) radikallerinin oluşumu spektrumda net bir biçimde gözlenmektedir. 


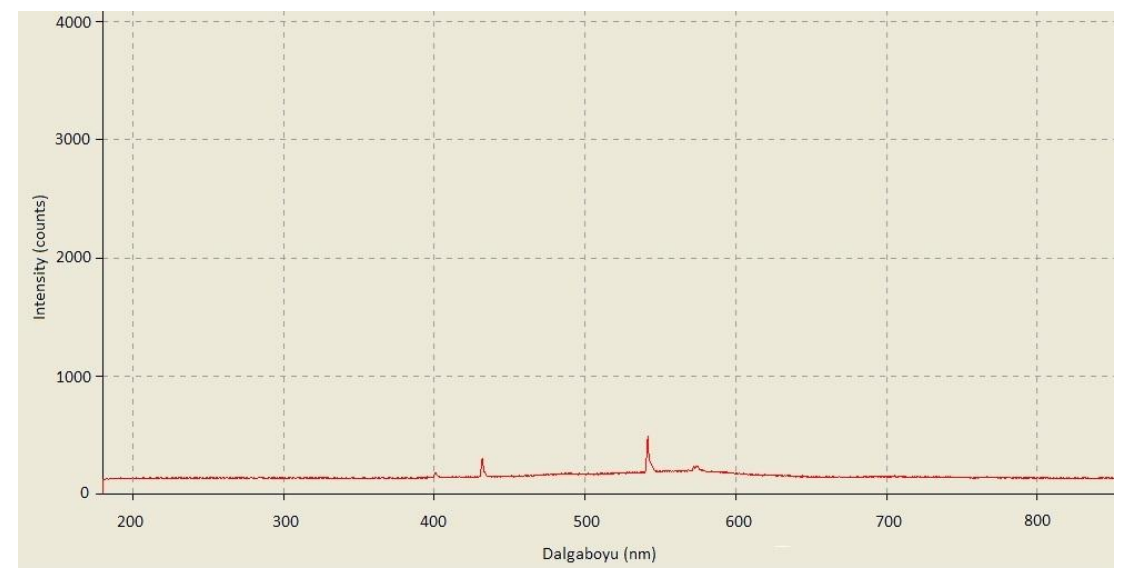

a)

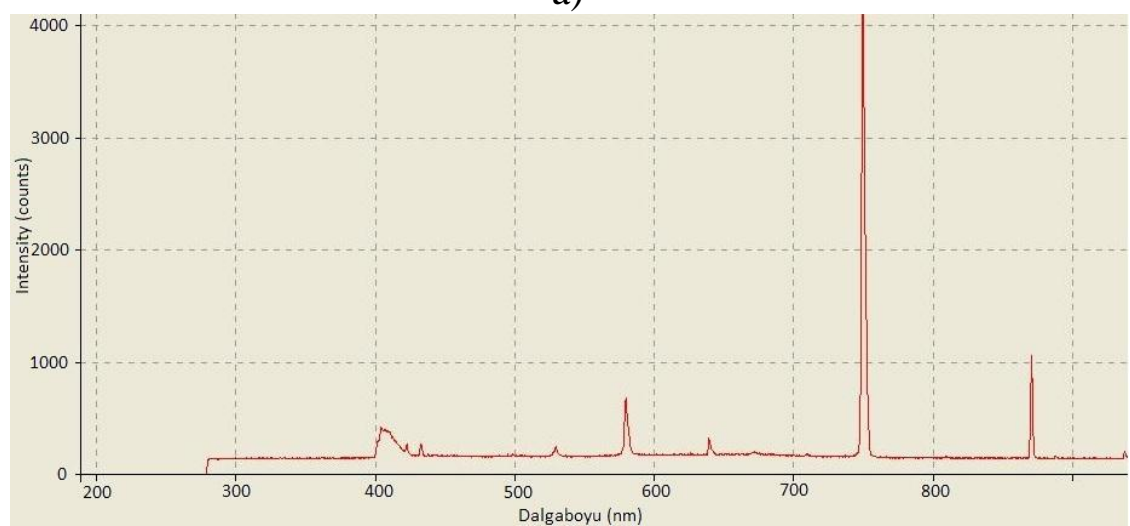

b)

Şekil 3. Çözelti İçerisinde Oluşan Plazmanın Optik Emisyon Spektrumları a) Plazma oluşmadan önce, b) Plazma oluştuktan sonra

$\mathrm{Bu}$ radikaller etkisiyle gümüş nitrat $\left(\mathrm{AgNO}_{3}\right)$ çözeltisi radikaller sayesinde gümüş atomuna kadar indirgenebilmektedir. (Plazma ortamında bulunan elektronların gümüş iyonlarını indirgrdiği düşünülmektedir, ancak eksilen artı yükün nasıl bir kimyasal tür oluşturduğu anlaşılamamıştır.) Plazma oluşumundan önce tamamen berrak olan gümüş nitrat çözeltisi, plazma oluştuktan sonra deşarj süresi arttıkça giderek koloidal bir hal almıştır.

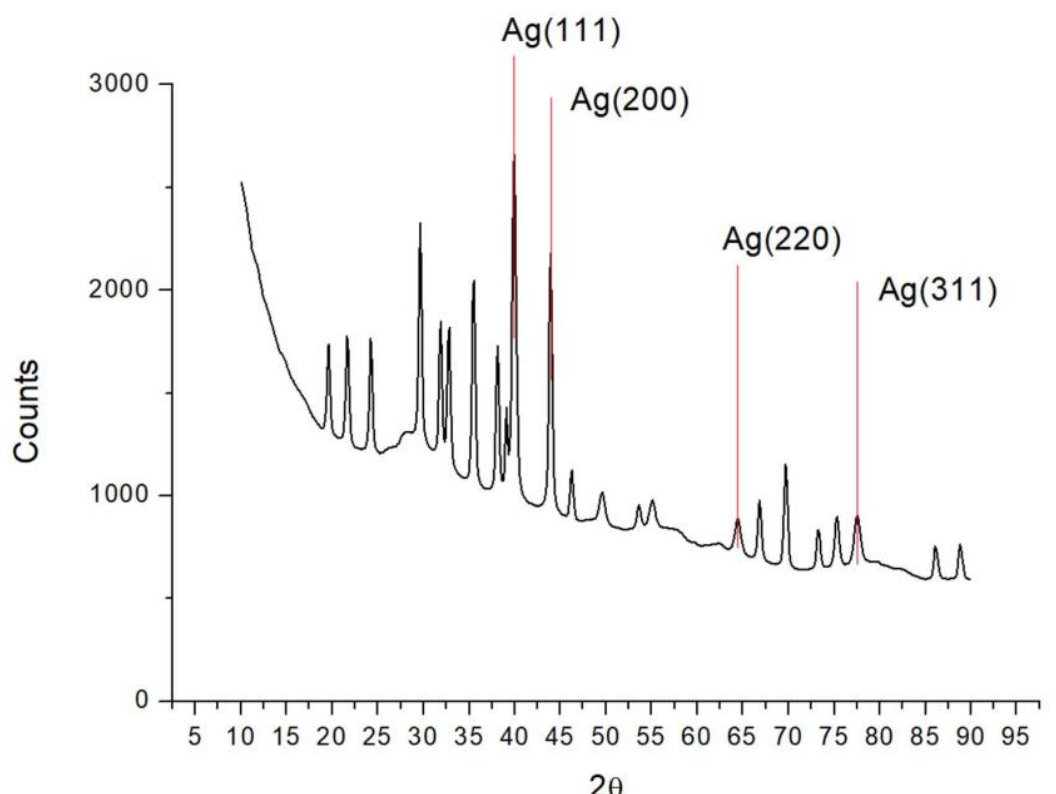

Şekil 4. AgNp ların XRD sonuçları. 
Tepkimeyle beraber çözelti siyahlaşmaya başlayıp tepkime hücresinin çeperlerinde ve tabanında siyah tanecikler gözlemlenmiştir. Deney sonunda erlen tabanına çökmüş gümüş tozları toplanıp kurutulmuş ve XRD ölçümü yapılmıştır. Elde edilen spektrum şekil-4'de gösterilmiştir. XRD desenine bakıldığında $38^{0}$ (111), $44^{0}(200), 64.5^{0}$ (220) ve $78^{0}$ (311) de gümüş pikleri gözlenmiştir. Her 10 dakikada alınan $5 \mathrm{ml}$ numuneler lam üzerine damlatılıp kurutulmuştur. $\mathrm{Bu}$ numunelerin FESEM ölçümleri sonuçları Şekil 5' de gösterilmiştir. Ayrıca $0.5 \mathrm{kV}$ lik gerilim altında alınan örneklerin 200-400 nm dalga boyu aralığında UV görünür spektrofotometre yardımı ile absorbansındaki değişimi incelenmiştir. Numunelerin absorbans değerlerini gösteren grafik de şekil-6'da gösterilmiştir. Elde edilen grafiklerde plazma süresinin artması ile çözeltinin absorbans değerinin düştüğü gözlenmiştir. Oluşan gümüş nanoparçacıkların boyut analizi FESEM ile yapılmış ve görüntüleri Şekil 5 gösterilmiştir.

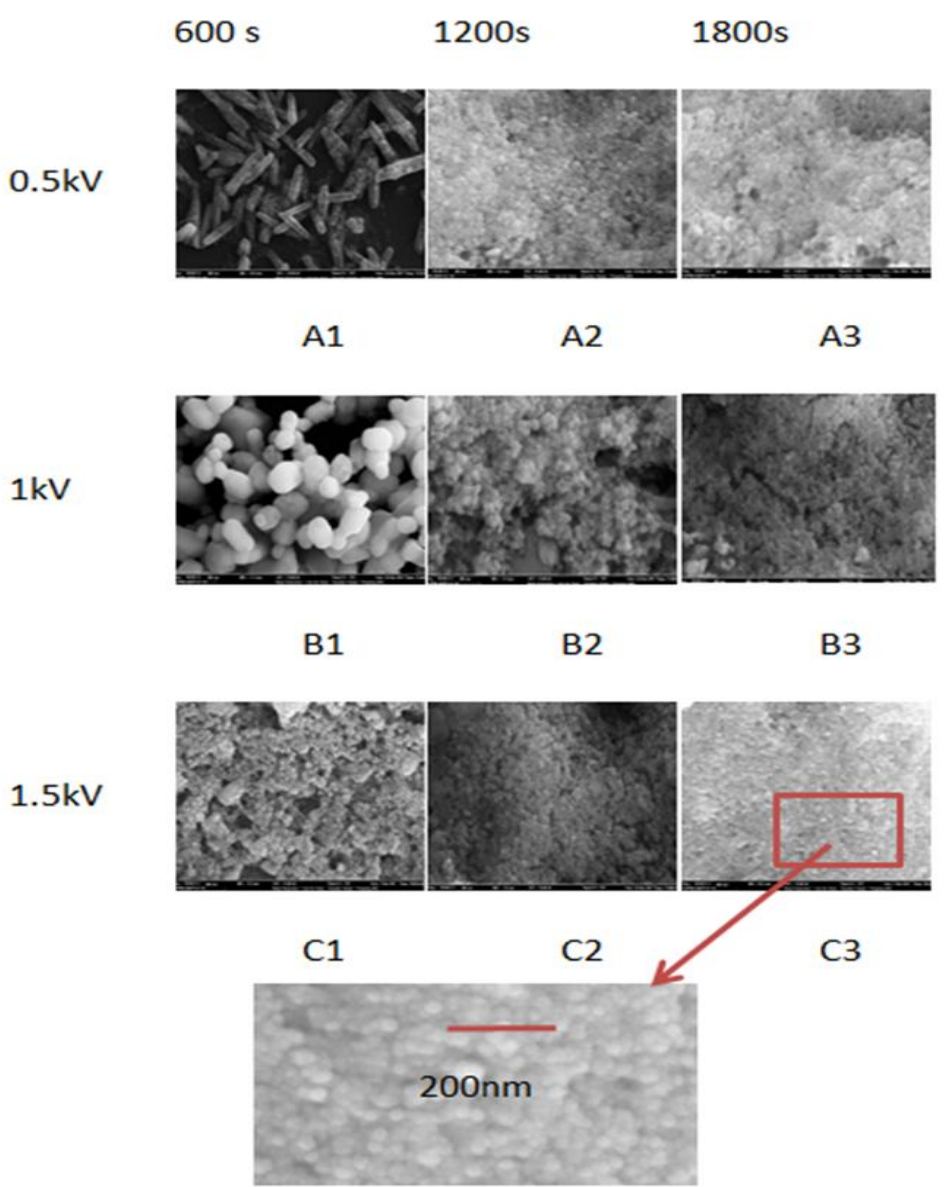

Şekil 5. $0.5 \mathrm{kV}, 1 \mathrm{kV}$ ve $1.5 \mathrm{kV}$ altında oluşturulan plazmada 10,20 ve 30 dakikalarda alınan numunelerin FSEM görüntüsü

\section{Sonuçlar}

$\mathrm{Bu}$ çalışma da sonuç olarak çözelti plazması yöntemi ile AgNp sentezlendi. Çalışma sonunda elde edilen AgNp ların boyutları FESEM görüntülerinden anlaşıldığı gibi $10 \mathrm{~nm}$ ile $40 \mathrm{~nm}$ arasında değişmektedir. Ayrıca plazma uygulama süresinin AgNp boyutlarına etkisi olduğu belirlenmiş ve süre arttıkça boyutların küçüldüğü gözlenmiştir. Bunun yanında voltaj etkisine bakıldığında yüksek voltajda daha hızlı şekilde küçük boyuta ulaşıldığı gözlenmiştir. Bu durum ilk $10 \mathrm{~s}$ deki FESEM görüntüleri incelendiğinde daha net anlaşılmaktadır. Plazma sürecinde oluşan radikallerin $\mathrm{AgNO}_{3}$ ün indirgenmesini sağlayarak AgNP'ların oluşumunu sağlamıştır. Plazma sürecinde 10 ar dakika ara ile alınan numunelerin absorbans eğrilerine bakıldığında sürenin artmasıyla absorbansın düştüğü 
gözlenmiştir. $\mathrm{Bu}$ çalışma özellikle sağlık sektöründe sıklıkla kullanılan AgNp üretimine katkıda bulunmuştur.

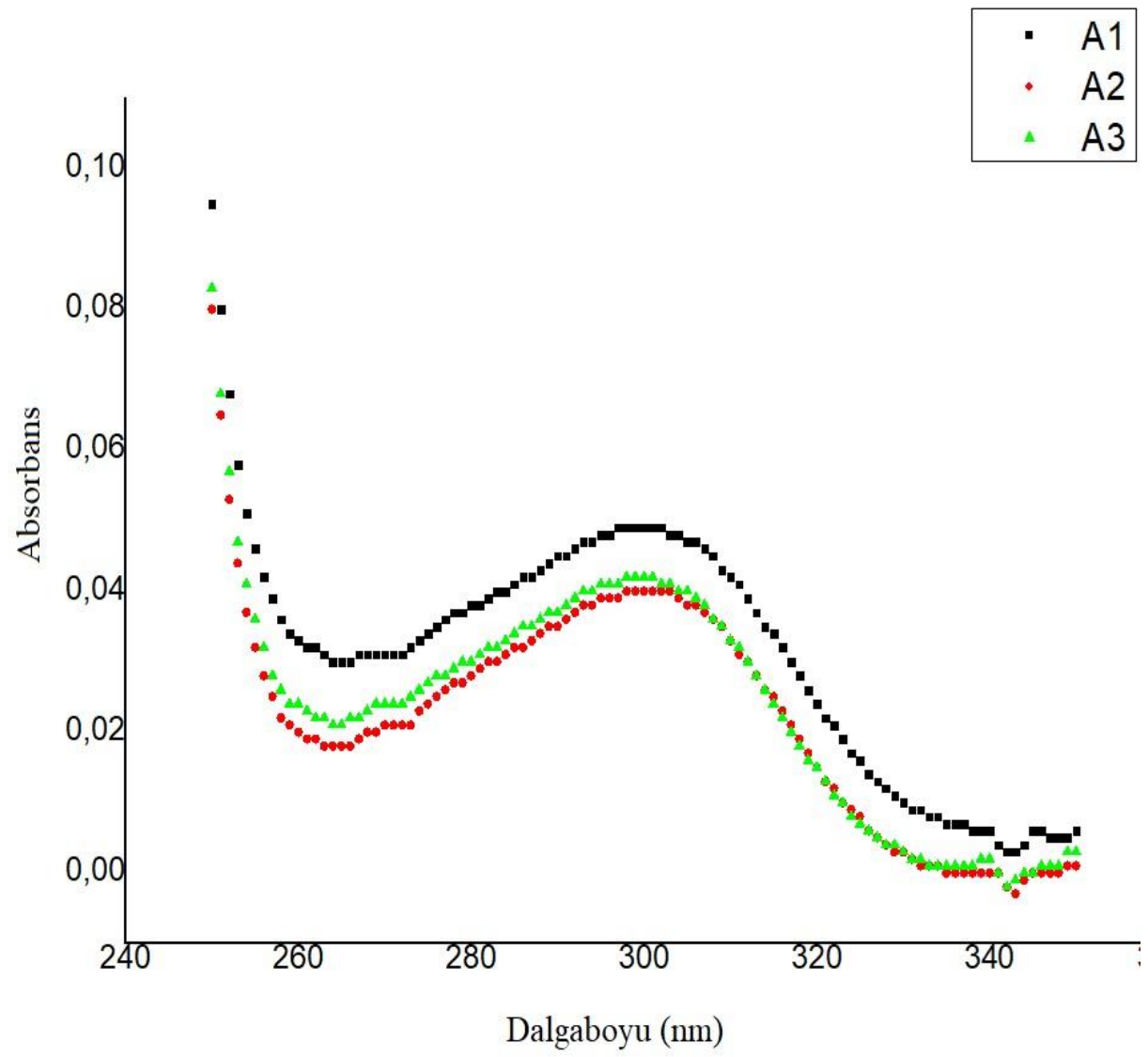

Şekil 6. $0.5 \mathrm{kV}$ altında 10 dakika ara ile alınan numunelerin absorbans grafiği

\section{Teşekkür}

$\mathrm{Bu}$ çalışma Afyon Kocatepe Üniversitesi Bilimsel Araştırma Projeleri (BAP) 17.FEN.BİL.04 numaralı proje tarafından kısmen desteklenmiştir.

\section{Kaynaklar}

[1]. Wen, X. G., Xie, Y. T., Mak, W. C., Cheung, K. Y., Li, X. Y., Renneberg, R., and Yang, S. H., Langmuir, 2006, 22, 4836.

[2]. Rashid,M. H. and Mandal, T. K., The Journal of Physical Chemistry C 2007 111 (45), 16750-16760.

[3]. Han, Y. C., Liu, S. H., Han, M., Bao, J. C. and Dai, Z. H., Cryst. Growth Des. 2009, 9, 3941. 81.

[4]. Fang, J., You, H., Zhu, C., Kong, P., Shi, M., Song, X. and Ding, B., Chem. Phys. Lett., , 2007,439, 204

[5]. Zhou, Q., Wang, S., Jia, N., Liu, L., Yang, J. and Jiang, Z.,Mater. Lett., 2006, 60, 3789.

[6]. Kim, K. D., Choi, K. Y. and Kim, H. T., Scripta Mater., 2005, 53, 571.

[7]. Takai, O., Solution Plasma Processing, Pure Appl. Chem., , 2008,Vol. 80, No. 9, pp. $2003-$ 2011

[8]. Saito, G., Akiyama, A., Nanomaterial Synthesis Using Plasma Generation in Liquid, Journal of Nanomaterials, 2015, 1-21. 
[9]. Akyüz, A., Özkan, M., Ağar, Ö., Polymer Degradation by Solution Plasma Technique: Online Monitoring of Viscosity, SDU Journal of Technical Sciences, 2016, 2, 1-6.

[10]. Akyüz, A., Özkan, M. Degradation of Polyvinylpyrrolidone by Solution Plasma Process, ACTA Physica Polonica, 2017, 131, 343-345.

[11]. Jin, S.-H., Kim, S.-M., Lee, S.-Y., Kim, J.-W., Synthesis and Characterization of Silver Nanoparticles Using a Solution Plasma Process, Nanoscience and Nanotechnology, 2014, 14, 8094-8097.

[12]. Hieda, ] J., Saito, N. and Takai, O.,Mater. Res. Soc. Symp. Proc., 2008, 1056, HH 03-39. 